\title{
Clinical audit of neonatal care in Assiut Women's Health Hospital, Egypt
}

\author{
Walaa S. Shehata ${ }^{1}$, Nafisa H. Refat ${ }^{2}$, Ali El Saman ${ }^{1}$, Mansour Y. Kandeel ${ }^{1}$, \\ Alaa M. Ismail ${ }^{1}$, Ahmed M. Abbas ${ }^{1 *}$
}

${ }^{1}$ Department of Obstetrics and Gynecology, ${ }^{2}$ Department of Pediatrics, Faculty of Medicine, Assiut University, Egypt

Received: 15 August 2017

Accepted: 09 September 2017

\section{*Correspondence:}

Dr. Ahmed M. Abbas,

E-mail: bmr90@hotmail.com

Copyright: (c) the author(s), publisher and licensee Medip Academy. This is an open-access article distributed under the terms of the Creative Commons Attribution Non-Commercial License, which permits unrestricted non-commercial use, distribution, and reproduction in any medium, provided the original work is properly cited.

\begin{abstract}
Background: The current study aims to auditing the current care of healthy full term newborns in the delivery room and identify the gap between the current practice and ideal practice in Assiut Women's Health Hospital, Egypt.

Methods: The current study was a clinical audit carried out in Assiut Woman Health Hospital, in the period from 1 September 2016 to 28 February 2017.The study included all newborns delivered in the delivery word of gestational age after 37 week. We excluded all Preterm babies, those with congenital anomalies, pregnant women with medical disorders and multiple pregnancies. In the present work all data was collected prospectively through direct personal patient contact, direct observation of care givers, patient interactions and attitudes, from the clinical records and then recording the data in special check sheet. All basic criteria of the study participants as age, parity, gestational age at delivery and type of delivery were obtained. The neonatal gender, weight, heart rate and respiratory rate were checked. Audit criteria were selected according to the WHO 2015 and AAP 2010-2015 guidelines.

Results: The study included 800 women; the mean age of the women was $26.52 \pm 5.70$ years. The mean parity was $1.78 \pm 1.85$. The mean gestational age at delivery was $38.81 \pm 0.96$ weeks. As regard the type of delivery, $54.1 \%$ of women were delivered by cesarean section. Calling neonatologists occurred in $67.9 \%$ of deliveries. The mean birth weight was $3.17 \pm 0.39$ kilograms. Nearly half of them $(52 \%)$ were males.

Conclusions: Application of the guidelines of the neonatal handling is important for optimum care to the neonates. Re-audit the steps of the handling is important to discuss whether practice has improved or not in our tertiary hospital.
\end{abstract}

Keywords: Clinical audit, Neonates, Resuscitation

\section{INTRODUCTION}

The UK's National Institute for Health and Clinical Excellence (NICE) defines clinical audit as: A quality improvement process that seeks to improve patient care and outcomes through systematic review of care against explicit criteria and the review of change. Aspects of the structure, process and outcome of care are selected and systematically evaluated against explicit criteria.
Where indicated changes are implemented at an individual, team, or service level and further monitoring is used to confirm improvement in healthcare delivery. ${ }^{1}$

The authors of the Cochrane Review on audit and feedback offer a narrower definition. For them clinical audit is: The provision of any summary of clinical performance over a specified period of time. ${ }^{2}$ Medical care of the full-term, healthy newborn in the delivery 
room has undergone numerous changes over past few years. One of the purposes being to decrease the excess of interventions performed on the newborn. There are evidences that most of the performed interventions are unnecessary, and some may even be harmful. ${ }^{3,4}$

Variations in practices used for the care of healthy newborns have been addressed in different situations, with different impacts on their health. Published data reports huge discrepancies between the existing scientific evidences and the medical practices. Furthermore, practitioners may not respond to evidences by implementing changes in policies and practices. This may be due to lack of knowledge or disagreement with the recommendations, but particularly due to local barriers for implementation. . $^{5,6}$

Approximately $10 \%$ of newborns require some assistance to begin breathing at birth. Less than $1 \%$ requires extensive resuscitation measures such as cardiac compressions and medications. ${ }^{7}$ Although most newly born infants successfully transition from intrauterine to extra uterine life without special help, because of the large total number of births, a significant number will require some degree of resuscitation. ${ }^{8}$

Being prepared is the first and most important step in delivering effective neonatal resuscitation. ${ }^{9}$ Neonates requiring resuscitation are inevitably born in locations where resuscitation is uncommon because most newborns are healthy and do not require additional special assistance. In these settings, the need for resuscitation is not anticipated in most infants who require resuscitation. ${ }^{10}$ As a result, at every birthing location, personnel who are adequately trained in neonatal resuscitation should be readily available to perform neonatal resuscitation whether or not problems are anticipated. ${ }^{9}$

The current study aims to auditing the current care of healthy full term newborns in the delivery room and identify the gap between the current practice and ideal practice in Assiut Women's Health Hospital, Egypt.

\section{METHODS}

The current study was a clinical audit carried out in Assiut Woman Health Hospital, in the period from 1 September 2016 to 28February 2017.The study included all newborns delivered in the delivery word of gestational age after 37 week.

The Assiut Medical Ethical Review Board approved the study. Informed consent was obtained from all study participants. We excluded all Preterm babies, those with congenital anomalies, pregnant women with medical disorders and multiple pregnancies.

In the present work all data was collected prospectively through direct personal patient contact, direct observation of care givers, patient interactions and attitudes, from the clinical records and then recording the data in special check sheet. All basic criteria of the study participants as age, parity, gestational age at delivery and type of delivery were obtained. The neonatal gender, weight, heart rate and respiratory rate were checked.

Audit criteria: we selected the criteria according to the WHO 2015 and AAP 2010-2015 guidelines that include the following items ${ }^{9}$

- Routine nasal or oral suction should not be done for babies born through clearamniotic fluid who start breathing on their own after birth.

- Intrapartum suction of mouth and nose at the delivery of head in neonates born through meconium is not recommended.

- Suctioning of mouth or nose is not recommended in neonates born through liquor with meconium who start breathing on their own.

- Tracheal suctioning should not be performed in newly born babies born through meconium who start breathing on their own.

- Late cord clamping (performed after one to three minutes after birth) is recommended for all births while initiating simultaneous essential newborn care.

- Early cord clamping ( $<1$ minute after birth) is not recommended unless the neonate is asphyxiated and needs to be moved immediately for resuscitation.

- Newborns without complications should be kept in skin-to-skin contact with their mothers during the first hour after birth to prevent hypothermia and promote breastfeeding.

- All newborns, including low-birth-weight (LBW) babies who are able to breastfeed, should be put to the breast as soon as possible after birth when they are clinically stable, and the mother and baby are ready

- All newborns should be given $1 \mathrm{mg}$ of vitamin $\mathrm{K}$ intramuscularly [IM] after birth [after the first hour during which the infant should be in skin-to-skin contact with the mother and breastfeeding should be initiated].

- Neonates requiring surgical procedures, those with birth trauma, preterm newborns, and those exposed in utero to maternal medication known to interfere with vitamin $\mathrm{K}$ are at especially high risk of bleeding and must be given vitamin $\mathrm{K} 1 \mathrm{mg}$ IM.

- After an uncomplicated vaginal birth in a health facility, healthy mothers and newborns should receive care in the facility for at least 24 hours after birth.

\section{Statistical analysis}

All data were analyzed using SPSS software Chicago, IL, USA, version 21. Categorical variables in both groups were presented as frequency and percentage. Continuous variables were presented as mean and standard deviation. 


\section{RESULTS}

Table 1 shows the baseline criteria of the study participants. The study included 800 women; the mean age of the women was $26.52 \pm 5.70$ years. The mean parity was $1.78 \pm 1.85$. The mean gestational age at delivery was $38.81 \pm 0.96$ weeks. As regard the type of delivery, $54.1 \%$ of women were delivered by cesarean section. Calling neonatologists occurred in $67.9 \%$ of deliveries.

Table 1: The baseline criteria of the study participants $(\mathbf{n}=\mathbf{8 0 0})$.

\begin{tabular}{|l|l|}
\hline Variables & $\begin{array}{c}\text { Study participants } \\
\text { Mean } \pm \text { SD (Range) }\end{array}$ \\
\hline Age (years) & $26.52 \pm 5.70(18-45)$ \\
\hline Parity & $1.78 \pm 1.85(0-8)$ \\
\hline Duration of marriage (years) & $2.49 \pm 1.45(1-10)$ \\
\hline Gestational age (weeks) & $38.81 \pm 0.96(37-41)$ \\
\hline Type of delivery, n (\%) & $367(45.9)$ \\
\hline Vaginal & $433(54.1)$ \\
\hline CS & $543(67.9)$ \\
\hline Calling neonatologist, n (\%) & $491 / 543(90.4)$ \\
\hline Respond to call, n (\%) & \\
\hline SD: standard deviation, CS: cesarean section
\end{tabular}

Table 2 shows the data of the newborns. The mean birth weight was $3.17 \pm 0.39$ kilograms. Nearly half of them $(52 \%)$ were males. Tables 3-5 show the clinical audit criteria and the percentage of fulfilling each item.

Table 2: The neonatal criteria at delivery of the study participants $(\mathbf{n}=\mathbf{8 0 0})$.

\begin{tabular}{|ll|}
\hline Variables & $\begin{array}{l}\text { Study participants } \\
\text { Mean } \pm \text { SD (Range) }\end{array}$ \\
\hline Birth weight & $3.17 \pm 0.39(2.0-5.0)$ \\
\hline Heart rate & $113.70 \pm 11.83(88.0-150.0)$ \\
\hline Respiratory rate & $52.28 \pm 5.28(40.0-60.0)$ \\
\hline Gender, n (\%) & \\
\hline Male & $416(52)$ \\
\hline Female & $384(48)$ \\
\hline SD: standard deviation & \\
\hline
\end{tabular}

Table 3 shows the most appropriate criteria regarding the preparedness for birth were presence of cord clamping devices $(99.3 \%)$, clean birth attendants' gloves $(97.1 \%)$, and presence of alcoholic solution $(95.8 \%)$ of cases. On the other hand, the criteria found with substandard care were; appropriate room temperature (82.3\%) and presence of a clean and pre-warm surface for resuscitation $(87.6 \%)$ of cases.

Table 3: Neonatal care at the birth and in the first 2 hours of life according the preparedness for the birth of 800 newborns which enrolled in the study.

\begin{tabular}{|c|c|c|c|c|}
\hline \multirow{2}{*}{ Items } & \multicolumn{2}{|l|}{ Yes } & \multicolumn{2}{|l|}{ No } \\
\hline & n & $\%$ & $\mathbf{n}$ & $\%$ \\
\hline The room temperature was appropriate $\left(25^{\circ} \mathrm{C}\right)$ & 658 & 82.3 & 142 & 17.8 \\
\hline The birth attendant's gloves (or hands if appropriate) were clean & 777 & 97.1 & 23 & 2.9 \\
\hline An alcoholic solution was available for cleaning hands quickly & 766 & 95.8 & 34 & 4.3 \\
\hline Sterile instruments were ready for use & 755 & 94.4 & 45 & 5.6 \\
\hline Cloths to dry and warm blankets to cover the infant were ready & 743 & 92.9 & 57 & 7.1 \\
\hline A clean and pre-warm surface was provided for resuscitation & 701 & 87.6 & 99 & 12.4 \\
\hline Resuscitation kit and suctioning device were clean, complete and ready to be used & 744 & 93.0 & 56 & 7.0 \\
\hline Cord clamping devices were present & 794 & 99.3 & 6 & 0.8 \\
\hline Eye prophylaxis ointment and intramuscular Vitamin $\mathrm{K}$ were available & 766 & 95.8 & 34 & 4.3 \\
\hline
\end{tabular}

Table 4: Clinical data of the 800 newborns regarding the assessment and immediate care.

\begin{tabular}{|c|c|c|c|c|}
\hline \multirow{2}{*}{ Items } & \multicolumn{2}{|l|}{ Yes } & \multicolumn{2}{|l|}{ No } \\
\hline & n & $\%$ & n & $\%$ \\
\hline The newborn was immediately dried after birth & 684 & 85.5 & 116 & 14.5 \\
\hline Newborn was placed on mother's abdomen or chest in skin to skin contact & 422 & 52.8 & 378 & 47.3 \\
\hline $\begin{array}{l}\text { The baby was assessed in the first } 30 \text { seconds after birth: start of breathing, tone and reactivity, } \\
\text { gestational age, presence of major malformations }\end{array}$ & 751 & 93.9 & 49 & 6.1 \\
\hline Appropriate actions were started, if needed, according to the clinical evaluation & 719 & 89.9 & 81 & 10.1 \\
\hline $\begin{array}{l}\text { Umbilical cord was clamped after at least one minute unless there is an immediate clinical need to } \\
\text { clamp early }\end{array}$ & 141 & 17.6 & 659 & 82.4 \\
\hline Stump of the umbilical cord was left without dressing & 524 & 65.5 & 276 & 34.5 \\
\hline Routine mouth and nose suctioning were done if indicated & 357 & 44.6 & 443 & 55.4 \\
\hline Routine catheterization to check patency of the esophagus was done & 356 & 44.5 & 444 & 55.5 \\
\hline $\begin{array}{l}\text { Mother and baby were covered together with a pre-warmed blanket, with the infant head turn to } \\
\text { the side }\end{array}$ & 361 & 45.1 & 439 & 54.9 \\
\hline A warm cap was put on the baby's head & 255 & 31.9 & 545 & 68.1 \\
\hline
\end{tabular}


Table 4 shows the most appropriate criteria regarding the assessment and immediate care was assessment of the baby in the first 30 seconds after birth (93.9\%). While, delayed umbilical cord clamping after at least one minute was only practiced among $17.6 \%$ of cases, and a warm cap around the baby's head in less than one third of cases.

Table 5: Data of the 800 neonates as regarding neonatal resuscitation.

\begin{tabular}{|c|c|c|c|c|}
\hline \multirow{2}{*}{ Items } & \multicolumn{2}{|l|}{ Yes } & \multicolumn{2}{|l|}{ No } \\
\hline & $\mathbf{n}$ & $\%$ & n & $\%$ \\
\hline $\begin{array}{l}\text { Written guidelines for resuscitation and care of the newborn were available, clearly } \\
\text { visible in the delivery room and implemented }\end{array}$ & 708 & 88.5 & 92 & 11.5 \\
\hline There was a resuscitation bed with a heating source and a suction equipment ready to use & 664 & 83.0 & 136 & 17.0 \\
\hline A functioning self-inflating bag with relief valve was available & 507 & 63.4 & 293 & 36.6 \\
\hline Term and premature size masks were available & 617 & 77.1 & 183 & 22.9 \\
\hline Suctioning device were available, in good working conditions and are adequately used & 712 & 89.0 & 88 & 11.0 \\
\hline $\begin{array}{l}\text { If a newborn infant was not breathing, resuscitation is initiated according to WHO } \\
\text { guidelines }\end{array}$ & 676 & 84.5 & 124 & 15.5 \\
\hline $\begin{array}{l}\text { There was a written procedure to have a senior health professional present or immediately } \\
\text { available for resuscitation in case of deliveries at risk of neonatal asphyxia }\end{array}$ & 716 & 89.5 & 84 & 10.5 \\
\hline Trained and skilled personnel (at least one professional) was available at every birth & 649 & 81.1 & 151 & 18.9 \\
\hline $\begin{array}{l}\text { Sequence, time and interventions performed during a resuscitation were recorded in } \\
\text { newborn profile }\end{array}$ & 505 & 63.1 & 295 & 36.9 \\
\hline $\begin{array}{l}\text { The infant was in skin contact with the mother immediately after birth and remains in } \\
\text { skin contact for at least } 60 \text { minutes (irrespective of feeding decision) and until after the } \\
\text { first breastfeed }\end{array}$ & 465 & 58.1 & 335 & 41.9 \\
\hline Bathing and weighing were informed to the parents & 277 & 34.6 & 523 & 65.4 \\
\hline
\end{tabular}

In Table 5, the most appropriate criteria regarding neonatal resuscitation was presence of written procedure to have a senior health professional present or immediately available for resuscitation in case of deliveries at risk of neonatal asphyxia in $89.5 \%$ of cases. On the opposite side, Bathing and weighing of the baby were informed to the parents in $34.6 \%$ of cases only

\section{DISCUSSION}

Every year, more than a million of the world's newborns die on their first day of life. ${ }^{11}$ According to van den Broek and Graham, the provision of quality care should be the central focus of efforts to achieve millennium development goals (MDG) targets for maternal and newborn health. ${ }^{12}$ Recent findings by Ajaari et al confirm that newborns delivered outside a health facility are more likely to die compared to newborns delivering in health facilities. $^{13}$

In the present study, we selected the topic of auditing neonatal care because it is a hot subject in which the medical care of the full-term, healthy newborn in the delivery room has undergone numerous changes, and most of the performed interventions are unnecessary, and some may even harmful. The main strengths of present study that it is a clinical audit with accurate collection of data not depending on routine records. We used the most recent international guidelines (WHO 2015 and AAP 2010-2015). ${ }^{9}$ Sufficient number of cases (800) enrolled in our study over reasonable period of time. The criteria and standards chosen were clear and measurable. A number of suggested recommendations were stetted to improve the quality of care and outcome. The main limitation of the present clinical audit that the loop of audit cycle is still open, there was no re-audit to evaluate if significant improvement in the quality of the service provided occurred or not.

\section{There are items presented with nearly optimal care in newborn care at our hospital}

According to the preparedness for the birth: The room temperature was appropriate $(25 \mathrm{c})$ in $82.3 \%$ of cases, the birth attendants' gloves were clean in $97.1 \%$ of cases, an alcoholic solution was available for cleaning hands quickly in $95.8 \%$ of cases, sterile instruments were ready for use in $94.4 \%$ of cases, clothes to dry and warm blankets to cover the infant were ready in $92.9 \%$ of cases, a clean and pre-warm surface was provided for resuscitation in $87.6 \%$ of cases, resuscitation kit and suctioning device were clean, complete and ready to be used in $93 \%$ of cases, cord clamping device were present in $99.3 \%$ of cases, and finally intra muscular Vitamin K was available in $95.8 \%$ of cases.

According to the newborn assessment and immediate care: The newborn was immediately dried after birth in $85.5 \%$ of cases, the baby was assessed in the first 30 seconds after birth: start of breathing, tone and reactivity, gestational age, presence of major malformation in $93.9 \%$ 
of cases, appropriate actions were started, if needed according to the clinical evaluation in $89.9 \%$ of cases.

According to neonatal resuscitation: Written guidelines for resuscitation and care of the newborn were available, clearly visible in the delivery room and implemented in $88.5 \%$ of cases, a resuscitation bed with a heating source and suction equipment ready to use in $83.0 \%$ of cases, suctioning device was available, in good working conditions and is adequately used in $89.0 \%$ of cases, if newborn infant was not breathing, resuscitation was initiated according to guidelines in $84.5 \%$ of cases. Additionally, there was a written procedure to have a senior health professional present or immediately available for resuscitation in case of deliveries at risk of neonatal Asphyxia in $89.5 \%$ of cases, lastly, trained and skilled personnel (at least one professional) were available at every birth in $81.1 \%$ of cases.

\section{Items with sub-standard care in newborn care at our hospital}

Lack the knowledge of skin to skin contact through placing the newborn on mother's abdomen or chest, missing delay cord clamping after one minute in case of there is no clinical need to clamp early, lack of the care of the stump of the umbilical cord was not left without dressing, the routine mouth and nose suctioning done for most newborns and this intervention should not be done except for the indicated cases, missing routine catheterization to check the patency of the esophagus, lack the knowledge about covering the mother and her newborn's together with a pre-warmed blankets, missing putting a warm cap on the baby's head, deficient sources in a functioning self-inflating bag with relief valve, term and preterm size masks. Also, inaccuracy in recording the sequence, time and interventions performed during resuscitation and finally, absence of counseling the parents about the bathing and weighing for the newborn.

Most causes of newborn mortality are preventable or treatable. Evidence-based interventions for prevention and treatment of the major causes of newborn mortalityprematurity, birth asphyxia, and infections-are well established and as well, studies have shown that use of quality improvement initiatives can be effective in applying these interventions to cause moderate reduction in the newborn mortality. ${ }^{14-17}$

\section{Recommendations}

Suggested recommendations for filling the gap to improve the newborn care and minimize complications:

- Training the residents and paramedical about the importance of skin to skin contact between the mother and her infant.

- Training the residents about the importance of delay cord clamping at least for one minute.
- Training the paramedical how to care the stump of the umbilical cord

- Training the residents, the need for neonatal resuscitation and admission to NICU.

- Training our residents and paramedical about the indications for suctioning the mouth and nose.

- Training our residents that routine catheterization to check patency of the esophagus is important and should be done.

- Identify the importance of covering the mother and the newborn together with a pre-warmed blanket.

- Identify the importance of putting a warm cap on the baby s head.

- Provide more functioning self-inflating bag with relief valve.

- $\quad$ Provide more term and preterm size masks.

- Recording the sequence, time and interventions performed during resuscitation in the infant profile.

- Counseling the parents about the bathing and weighing for the newborn.

- Counseling the parents about the importance of breastfeeding immediately after birth and early skin to skin contact.

- Good counseling for the parents about the symptoms of hyperbilirubinemia.

- Counseling the parents about the importance of follow-up visit. The most important recommendation is to re-audit to discuss whether practice has improved or not.

Funding: No funding sources

Conflict of interest: None declared

Ethical approval: The study was approved by the Institutional Ethics Committee

\section{REFERENCES}

1. Excellence, NIfC 2002, Principles for best practice in clinical audit, Radcliffe Publishing;2002.

2. Jamtvedt G, Young JM, Kristoffersen DT, O'Brien MA, Oxman AD. Audit and feedback: effects on professional practice and health care outcomes. Cochrane Database Syst Rev. 2006;2:CD000259.

3. Perlman JM, Wyllie J, Atkins DL, Chameides L, Goldsmith JP, Guinsbirg R, et al. Part 15: Neonatal resuscitation: 2010 international consensus on cardiopulmonary resuscitation and Emergency cardiovascular care science with treatment Recommendations. Pediatrics. 2010;126(5):e131944.

4. Kiremitici S, Tuzun F, Yesilirmak DC, Kumral A, Duman N, Ozkan H. Is gastric aspiration needed for newborn management in delivery room? Resuscitation. 2011;82:40-4.

5. Acolet D. Quality of neonatal care and outcome. Arch Dis Child Fetal Neonatal Ed. 2008;93:F69-73.

6. Soll RF. Evaluation the medical evidence for quality improvement. Clin Perinatal. 2010;37:11-28. 
7. Barber CA, Wyckoff MH. Use and efficacy of endotracheal versus intravenous epinephrine during neonatal cardiopulmonary resuscitation in the delivery room. Pediatrics. 2006;118(3):1028-34.

8. Kattwinkel J, Perlman JM, Aziz K, Colby C, Fairchild K, Gallagher J et al. Neonatal resuscitation: 2010 American Heart Association Guidelines for Cardiopulmonary Resuscitation and Emergency Cardiovascular Care. Pediatrics. 2010;126:e1400-13.

9. Wyckoff MH, Aziz K, Escobedo MB, Kapadia VS, Kattwinkel J, Perlman JM et al. Part 13: Neonatal Resuscitation: 2015 American Heart Association Guidelines Update for Cardiopulmonary Resuscitation and Emergency Cardiovascular Care. Circulation. 2015;132(18 Suppl 2):S543-60.

10. Mitchell A, Niday P, Boulton J, Chance G, Dulberg C. A prospective clinical audit of neonatal resuscitation practices in Canada. Adv Neonatal Care. 2002;2,(6):316-26.

11. Save the Children: Surviving the first day: State of the World's Mothers 2013. Westport, CT: Save the Children; 2013.

12. van den Broek N, Graham W. Quality of care for maternal and newborn health: the neglected agenda. BJOG. 2009;116(Suppl. 1):18-21.

13. Ajaari J, Masanja H, Weiner R, Abokyi SA, OwusuAgyei S. Impact of place of delivery on neonatal mortality in rural Tanzania. Int $\mathrm{J} \mathrm{MCH}$ AIDS. 2012;1(1):49-59.
14. Lassi ZS, Haider BA, Bhutta ZA. Community-based intervention packages for reducing maternal and neonatal morbidity and mortality and improving neonatal outcomes. Cochrane Database Syst Rev. 2010;11:CD007754.

15. Wall SN, Lee AC, Carlo W, Goldenberg R, Niermeyer S, Darmstadt GL et al. Reducing intrapartum-related neonatal deaths in low- and middle-income countries: What works? Semin Perinatol. 2010;34(6):395-407.

16. Lee AC, Cousens S, Wall SN, Niermeyer S, Darmstadt GL. Neonatal resuscitation and immediate newborn assessment and stimulation for the prevention of neonatal deaths: A systematic review, meta-analysis and Delphi estimation of mortality effect. BMC Public Health. 2011;11(Suppl 3):S12.

17. Galadanci H, Künzel W, Shittu O, Zinser R, Gruhl M, Adams S. Obstetric quality assurance to reduce maternal and fetal mortality in Kano and Kaduna State Hospitals in Nigeria. Int $\mathbf{J}$ Gynecol Obstet. 2011;114:23-28.

Cite this article as: Shehata WS, Refat NH, El Saman A, Kandeel MY, Ismail AM, Abbas AM. Clinical audit of neonatal care in Assiut Women's Health hospital, Egypt. Int J Reprod Contracept Obstet Gynecol 2017;6:4252-7. 